\title{
Patient and public attitudes to and awareness of clinical practice guidelines: a systematic review with thematic and narrative syntheses
}

Kirsty Loudon ${ }^{1 *}{ }^{*}$, Nancy Santesso ${ }^{2+}$, Margaret Callaghan ${ }^{3}$, Judith Thornton ${ }^{4}$, Jenny Harbour ${ }^{3}$, Karen Graham ${ }^{3}$, Robin Harbour ${ }^{3}$, Ilkka Kunnamo ${ }^{5}$, Helena Liira ${ }^{3}$ Emma McFarlane ${ }^{4}$, Karen Ritchie ${ }^{3}$ and Shaun Treweek ${ }^{6}$

\begin{abstract}
Background: Clinical practice guidelines are typically written for healthcare providers but there is increasing interest in producing versions for the public, patients and carers. The main objective of this review is to identify and synthesise evidence of the public's attitudes towards clinical practice guidelines and evidence-based recommendations written for providers or the public, together with their awareness of guidelines.

Methods: We included quantitative and qualitative studies of any design reporting on public, patient (and their carers) attitudes and awareness of guidelines written for providers or patients/public. We searched electronic databases including MEDLINE, PSYCHINFO, ERIC, ASSIA and the Cochrane Library from 2000 to 2012. We also searched relevant websites, reviewed citations and contacted experts in the field. At least two authors independently screened, abstracted data and assessed the quality of studies. We conducted a thematic analysis of first and second order themes and performed a separate narrative synthesis of patient and public awareness of guidelines.
\end{abstract}

Results: We reviewed 5415 records and included 26 studies (10 qualitative studies, 13 cross sectional and 3 randomised controlled trials) involving 24887 individuals. Studies were mostly good to fair quality. The thematic analysis resulted in four overarching themes: Applicability of guidelines; Purpose of guidelines for patient; Purpose of guidelines for health care system and physician; and Properties of guidelines. Overall, participants had mixed attitudes towards guidelines; some participants found them empowering but many saw them as a way of rationing care. Patients were also concerned that the information may not apply to their own health care situations. Awareness of guidelines ranged from 0-79\%, with greater awareness in participants surveyed on national guideline websites.

Conclusion: There are many factors, not only formatting, that may affect the uptake and use of guideline-derived material by the public. Producers need to make clear how the information is relevant to the reader and how it can be used to make healthcare improvements although there were problems with data quality. Awareness of guidelines is generally low and guideline producers cannot assume that the public has a more positive perception of their material than of alternative sources of health information.

Keywords: Clinical practice guidelines, Patient, Public, Attitudes, Awareness

\footnotetext{
* Correspondence: k.loudon@dundee.ac.uk

${ }^{\dagger}$ Equal contributors

'Division of Population Health Sciences, University of Dundee, Kirsty Semple

Way, Dundee DD2 4BF, UK

Full list of author information is available at the end of the article
} 


\section{Background}

Clinical practice guidelines are systematically developed tools that present recommendations and research evidence to direct appropriate healthcare throughout the world. They are typically produced for health care providers but there is an increasing interest in developing derivative products for the public. A recent review of existing programmes for patient and public involvement in guidelines found that almost half of the reports indicated that patients were involved in the development of products specifically for patients and the public [1]. In addition, there are now many organisations producing patient versions of guidelines. In the UK, for example, the National Institute for Health and Care Excellence (NICE) and the Scottish Intercollegiate Guidelines Network (SIGN) produce freely accessible patient versions. The Finnish Medical Society, Duodecim, publishes patient versions of national Current Care guidelines at and a comprehensive collection of guideline-based patient information in Duodecim's Health Library. Professional groups are also producing patient versions of their guidelines, for example, the Netherlands Association of Posttraumatic Dystrophy.

The research base for presentation and uptake of patient versions of guidelines is also growing. Much of the research draws on work about how to present evidence to patients in different formats - the GIN toolkit [2] for example - and how to develop decision aids from guidelines to promote the use and uptake of guidelines by patients and the public [3,4]. However, we know that other factors play an important role in the use of evidence and guidelines. Graham and Logan, for example, describe the characteristics of the patient as an important factor which could act as a barrier or facilitator to uptake [5]. These characteristics would include patient and public attitudes towards guidelines, and awareness of guidelines. The literature suggests, for example, that consumers may perceive guidelines negatively as a way to ration access to medications [6], a perception that would need to be addressed by material intended for the public.

The main objective of this review was to identify and synthesise evidence on the public's attitudes towards clinical practice guidelines (including related patient versions) and evidence-based recommendations, as well as on their awareness. This work is part of a larger project which focuses on the communication of guidelines to a variety of target audiences in the DECIDE project (Developing and Evaluating Communication Strategies to support Informed Decision and practice based on Evidence: http://www.decide-collaboration.eu) [7].

\section{Methods}

We conducted a synthesis of quantitative and qualitative studies similar to the approach used by Smith [8] and based on the methodology described by Dixon-Woods [9] and Munro [10]. We have reported this review using the guidance provided in the ENTREQ statement, an EQUATOR Network reporting guideline for the synthesis of qualitative research [11].

\section{Inclusion and exclusion criteria}

We included quantitative and qualitative studies of any design reporting on the attitudes and awareness of guidance or guidelines, both for health care providers and patients and the public (patient versions). Other inclusion and exclusion criteria are given in Table 1.

\section{Identification of studies}

We searched MEDLINE, MEDLINE In Process, PSYCHINFO, ERIC, ASSIA from 2000 to January 2012 using key terms for patients, guidelines or guidance, awareness, perception, attitudes, communication and information dissemination (see Additional file 1 for the search strategies for principal databases). We updated our MEDLINE search up to January 2013. We conducted a search for secondary research in The Cochrane Library, Guidelines International Network (G-I-N) conference abstracts, Picker institute, Health Talk Online, Health Foundation, World Health Organisation, King's Fund, Biomed Central, National Institutes of Health, NLM, AHQR, OpenDOAR, The Knowledge Network, NHS Evidence, TRIP database, Intute (up to January 2012), Google (including Google Scholar), Dogpile, and Health on the Net Foundation for documents published between 1999 and 2012. We also reviewed citations from key documents, authors and institutions (published between 1999 to 2012), and contacted experts in the field via emails to members of the DECIDE project, GRADE Working Group G-I-N and the Evidence Based Health discussion list (April 2012).

At least two authors independently screened each citation by title and abstract. We then retrieved the full text of all citations identified as potentially relevant by at least one investigator and two authors independently screened these full texts. Articles in English, Finnish, Norwegian, Spanish and German were included.

\section{Data extraction}

Two authors independently extracted data from the included studies using a form which was first piloted and revised accordingly. Extracted data included study design and methods, recruitment strategy, study setting, number of participants, characteristics of participants (including age, sex, ethnicity, socio-economic status, and education level of participants), details of the interventions used to communicate guideline information, and awareness of clinical practice guidelines. From each study, we used an inductive approach to identify first order themes (i.e. themes 
Table 1 Inclusion and exclusion criteria

\begin{tabular}{l} 
Inclusion criteria \\
\hline $\begin{array}{l}\text { Public, patient or carer beliefs, feelings, awareness, understanding, } \\
\text { knowledge, attitudes, expectations and perceptions of clinical } \\
\text { practice guidelines (and/or guidance). }\end{array}$ \\
User-testing of public/patient information tools derived from guidelines. \\
Readability/understandability of public/patient-targeted information \\
materials derived from guidelines. \\
Communicating research results to public/patients within the context \\
of a guideline. \\
Public/patient versions of guidelines \\
Computer interpretable guidelines for public/patients.
\end{tabular}

Knowledge translation tools for public/patients derived from guidelines.

\section{Exclusion criteria}

Opinion pieces, editorials, narrative reviews and protocols.

Public/patient involvement in guideline development.

Public/patient-centred communication/information not related to guidelines or evidence-based recommendations.

\author{
Public health campaigns. \\ and their consequences). \\ Informed consent for clinical trials. \\ Public understanding of science.
}

Procedure-specific information (e.g. details of surgical operations based on the participants' understanding reported by the authors) and second order themes (i.e. themes from the authors' interpretation of the findings) related to attitudes and awareness of clinical practice guidelines.

\section{Quality assessment of studies}

There is no agreed tool to assess the reliability of studies for qualitative research; we used the CASP (Critical Appraisal Skills Programme) tools [10]. Two reviewers independently assessed the methodological quality of the included quantitative and qualitative studies using the relevant CASP tool $[12,13]$. Studies were rated as good, fair or poor by considering all of the factors, but in particular, whether the study used a qualitative methodology appropriately to address our objectives.

\section{Data synthesis}

Two reviewers compared the data extracted from all studies and resolved disagreements by discussion. We reported the awareness of guidelines for each study, and also a range across the studies, as we could not pool this data.

For the analysis of qualitative data, we based our analysis on approaches described by Smith [8], DixonWoods [9] and Munro [10] and conducted a thematic analysis [14]. Two reviewers first compared the themes extracted from each study to develop consensus. All themes (first and second order) were then compiled across the studies and the two reviewers organised the themes to develop categories of dominant themes with subthemes. Each paper was then recoded according to the categories of overarching and subthemes. This process was iterative with discussion between the two reviewers, and also involved consultation with the team.
Quotes from the original studies were used to illustrate the themes.

\section{Results}

\section{Selection of studies}

We found 5415 unique records with the database search and five additional studies through other methods. We assessed 183 studies as potentially eligible and retrieved those in full text. After full-text screening, 26 studies, involving 24887 individuals were included in the review (see Figure 1 for the PRISMA Diagram of flow of studies). Of the 26, 20 studies provided data for the thematic analysis and 17 studies provided data for the awareness of clinical practice guidelines.

\section{Study characteristics}

There were ten qualitative studies using focus groups or semi-structured interviews [6,15-23]; thirteen cross sectional studies [24-36]; and three randomised controlled trials: [37-39].

Tables 2 and 3 provide the characteristics of the included studies. Overall the studies included diverse populations: Canadian office workers, female carers in Maryland, USA, Londoners attending drop-in centres in the UK for patients with mental health problems, visitors to a welfare centre in Seoul, women attending secondary care for menstrual abnormalities in Leicestershire, UK, and patients with Diabetes in Australia. The age of participants ranged from 30 to over 76 years, apart from one study on 11-15 year old adolescents [33]. Most studies included both genders although some included only women because of the topic (e.g. breast cancer).

The qualitative research studies were mostly good to fair quality (Tables 2 and 3). Common reasons for fair 


\section{PRISMA 2009 Flow Diagram}
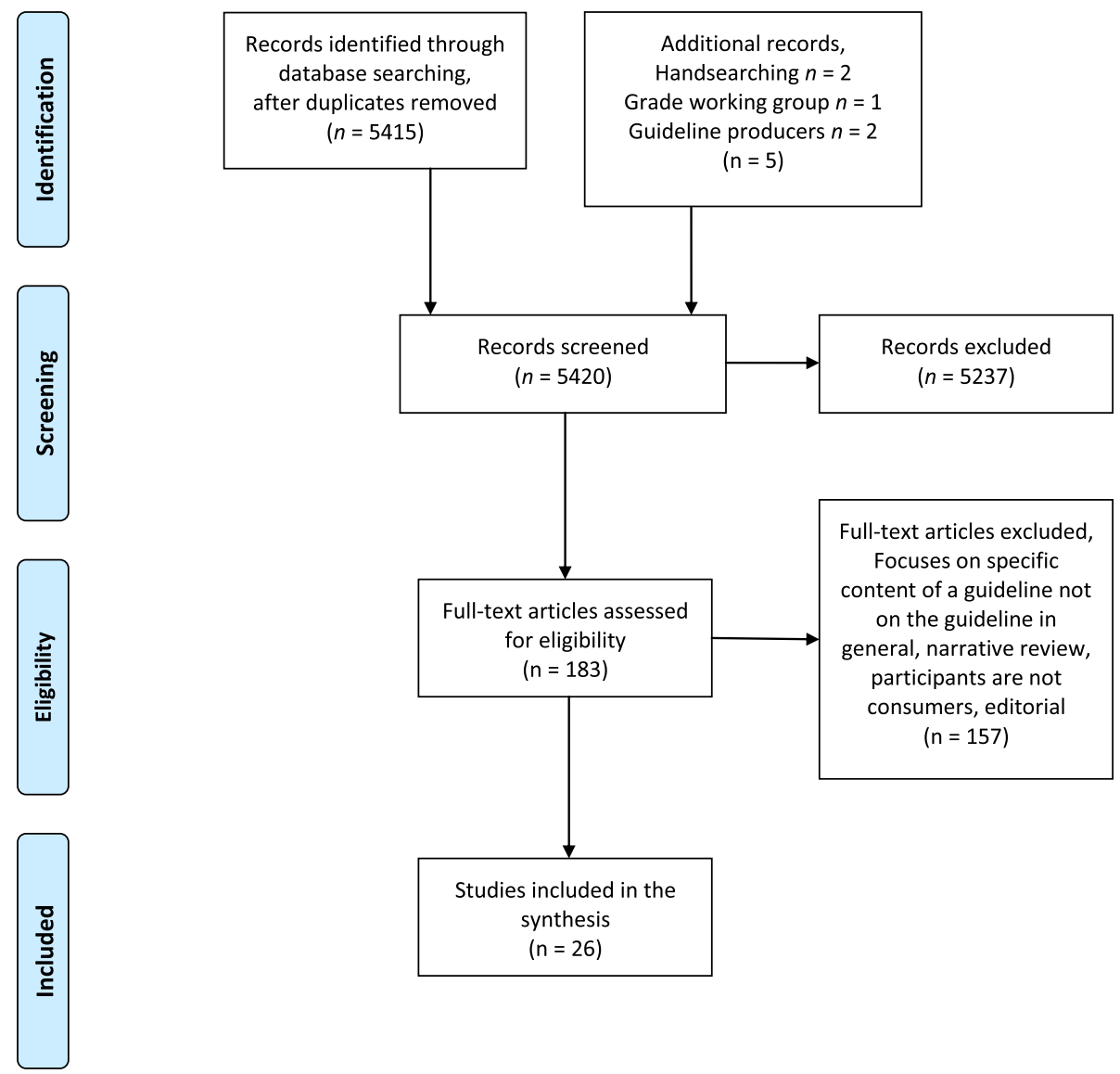

Figure 1 PRISMA diagram of flow of studies. From: Moher D, Liberati A, Tetzlaff J, Altman DG, The PRISMA Group (2009). Preferred Reporting Items for Systematic Reviews and Meta-Analyses: The PRISMA Statement. PLoS Med 6(6): e1000097. doi:10.1371/journal.pmed1000097 For more information, visit www.prisma-statement.org.

quality were: lack of description or discussion about the analyses of the qualitative data reported in primarily quantitative studies; the role of the researcher and their relationship with the participants when conducting the focus groups or interviews; and whether or not saturation of data was reached. Most of the quantitative studies were also good to fair quality. Few included information about pre-testing questionnaires, or had poor response rates and/or high drop-out rates.

Thematic analysis of the public's attitudes towards clinical practice guidelines and evidence based recommendations The thematic analysis of the included studies resulted in four overarching themes and sub-themes for the patient and public attitudes towards clinical practice guidelines:

- Applicability of guidelines: Patient as individual, Applicability of information to themselves
- Purpose of guidelines for patient: Communicate with physician; Decision making; Self-management

- Purpose of guidelines for health care system and physician: Guidelines control care (restrict/offer, access, cost); Guidelines as rules

- Properties of guidelines: Format issues; Trustworthiness; Evidence behind recommendations

Theme 1: Applicability of guidelines

Several studies reported that individuals expressed concern that guidelines may not personally help them and may not be applicable to their particular needs $[6,18,23,26,27,38]$. Two studies highlighted that treatment decisions should be tailor made to the individual and therefore guidelines may not be appropriate $[6,18]$. Although Julian [18] also indicated in a qualitative study of women with menstrual disorders that this may not be true for all patients and that: 
Table 2 Characteristics of studies and themes identified in thematic analysis of attitudes to clinical practice guidelines (19 included studies)

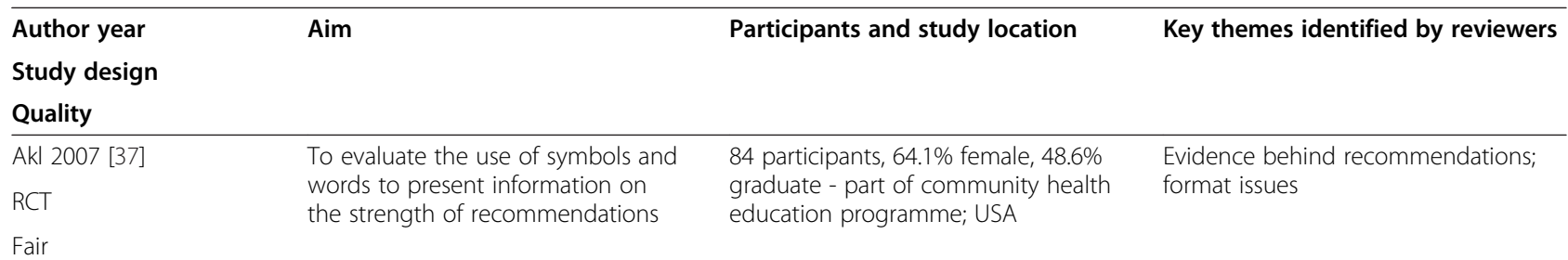

Berry 2010 [23]

Qualitative study

Good

Carman 2010 [6]

Qualitative study

Fair

Crocetti 2004 [26]

Cross sectional study

Good

Dykes 2004 [15]

Qualitative study

Poor

Eaton 2011 [38]

$\mathrm{RCT}$ cluster randomised Good

\section{Elad 2011 [27]}

Cross sectional study

Good

Faruqi 2000 [16]

Qualitative study

Poor

Geiger 2001 [17]

Qualitative study

Poor

Julian 2010 [18]

Qualitative study

Good

Keenan 2002 [29]

Cross sectional study

Fair

McFarlane 2012 [30]

Cross sectional study

Fair
To gain an understanding of public perceptions of Physical Activity guidelines put forward by a public health agency

To determine how the concept of making health care decisions based on evidence of effectiveness could be translated into language that consumers would understand

To determine awareness and knowledge of infant feeding guidelines

To evaluate a tool to drive patient centred evidence based recommendations to facilitate guideline adherence

To determine whether an intervention based on patient activation and a physician support tool was more effective than usual care to improve adherence to National Cholesterol Education Program guidelines (USA)

To gauge acceptance of 2007 American Heart Association guidelines on antibiotic prophylaxis after being notified about change by doctor

To determine views, how to put into practice and disseminate clinical management of diabetes mellitus guidelines

To determine awareness of dietary guidelines and test presentation formats

To determine knowledge and attitudes of women with menstrual disorders towards the use of evidence based clinical guidelines for their condition

To examine knowledge and understanding and factors that influence knowledge - media/ nonmedia/age and education

To determine public awareness of National Institute for Health and Care Excellence (NICE) guidelines and their implementation
22 participants in five focus groups, 18 to 70 years; Type II diabetes or cardiovascular disease; Canada

34 consumers in 4 focus groups, 57 interviews and 1558 employees, 18-64; USA

102 Primary female caregivers mean age 27 years; 34\% African American; $64 \%$ completed high school; Maryland, USA

3 evaluators mean age 71 years, TV literate bedbound patients and carers (higher retirement income); Connecticut, USA

4105 patients; primary care; mean age 52 control/54 intervention; $96 \%$ white; $59 \%$ female, southeastern New England, USA.

51 patients, $58 \pm 17$ yrs, $40 \%$ female with endocarditis; Israel.

5-20 participants recruited through Diabetes Australia in four focus groups; Sydney, Australia

40 men and women (25-45); Missouri, USA

24 women (22-54) attending secondary care; Leicestershire, England

400 adults over 18 years old, $51.8 \%$ college degree, $56 \%$ female; Minnesota, USA

1675 respondents (70\% female, $61 \%$ (45-74 yrs old), 17\% health care professionals); mostly England and Wales, UK
Patient as individual; format issues

Patient as individual; Guidelines control care; Guidelines as rules; Guidelines for physicians; Communicate with physician; Trustworthiness

Patient as individual

Self management; Format issues

Communicate with physician, decision making; Self management; Patient as individual. Format issues

Applicability of guideline information; Communicate with physician; Trustworthiness

Self-management; Communicate with physician; Guidelines for physicians; Format issues

Guidelines for physicians; Guidelines control care; format issues

Guidelines as rules; Guidelines control care; Guidelines for physicians; Patient as individual;

Format issues

Guidelines for physicians; Guidelines control care 
Table 2 Characteristics of studies and themes identified in thematic analysis of attitudes to clinical practice guidelines (19 included studies) (Continued)

\begin{tabular}{|c|c|}
\hline Michie 2005 [39] & \multirow[t]{2}{*}{$\begin{array}{l}\text { To evaluate knowledge of guideline } \\
\text { and take up when using } \\
\text { behaviourally specific language }\end{array}$} \\
\hline Poor & \\
\hline Cross sectional study & \multirow[t]{2}{*}{$\begin{array}{l}\text { To determine awareness of infection } \\
\text { control guidelines }\end{array}$} \\
\hline Fair & \\
\hline Mitchell 2004 [19] & \multirow[t]{2}{*}{$\begin{array}{l}\text { To determine knowledge of } \\
\text { evidence based medicine and } \\
\text { guidelines }\end{array}$} \\
\hline Fair & \\
\hline Owen-Smith 2010 [20] & $\begin{array}{l}\text { To investigate patients' and } \\
\text { healthcare providers' experiences } \\
\text { of, and preferences for, implicit } \\
\text { and explicit healthcare rationing }\end{array}$ \\
\hline Quintana 2001 [21] & \multirow{2}{*}{$\begin{array}{l}\text { To explore how best to use the } \\
\text { Internet to make evidence-based } \\
\text { preventive health care guidelines } \\
\text { available to physicians and } \\
\text { consumers }\end{array}$} \\
\hline Good & \\
\hline Royak-Schaler 2008 [22] & \multirow[t]{2}{*}{$\begin{array}{l}\text { To investigate patient-physician } \\
\text { communication from the patient's } \\
\text { perspective about guidelines }\end{array}$} \\
\hline Fair & \\
\hline Cross sectional study & $\begin{array}{l}\text { To investigate public awareness of } \\
\text { Scottish Intercollegiate Guidelines } \\
\text { Network (SIGN) guidelines and } \\
\text { their implementation }\end{array}$ \\
\hline Squiers 2011 [35] & $\begin{array}{l}\text { To assess how knowledgeable } \\
\text { women were about the new } \\
\text { recommendations in mammography }\end{array}$ \\
\hline
\end{tabular}

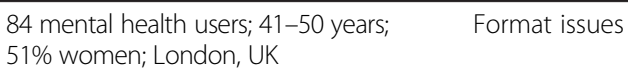

33 patients with colorectal cancer and 9 carers, 43 to 86 years; $66 \%$ male, many had not completed high school; Austin, Victoria, Australia

56 participants (31 patients, clinicians, healthcare managers); morbid obesity and breast cancer; Bristol, UK

39 participants (22 men, 17 women, $56 \%$ men), 35 to 65 years, experience using the Internet; Canada.

39, age 30-75 (mean age 55), 72\% college education, breast cancer survivors, all African American; Baltimore, USA

239 respondents (66\% female, 74\% 45-74 yrs old, 61\% had specific condition or disability); mostly Scotland, UK

1221 women, 40-74, who had never had breast cancer; USA
Communicate with physician

Communicate with physician

Guidelines control care

Format issues; self management; Trustworthiness; evidence behind recommendations; Communicate with physician; Decision making

Self-management; Communicate with physician

Format issues; Evidence behind recommendations; Guidelines improve care; Guidelines for physicians

Format issues; Evidence behind recommendations; Guidelines control care

Good

RCT: randomised controlled trial.

Patients' perception of clinical guidelines was also influenced by whether they viewed menstrual disorders as being unique to the individual patient and requiring personal treatment or as a process in which women experience similar symptoms requiring similar treatment.

Participants were inclined to trust their judgement based on their own unique experiences $[6,26]$ or advice from others in similar situations rather than trust guidelines [18]. For instance, while the majority of women in a survey knew the guideline recommendations were not to give solid food to infants before four months, almost half did give their child cereal before the age of four months and more than $40 \%$ reported that the advice of a friend or family member was influential in this decision [26]. Participants also wanted to clearly see that guidelines could apply to them. When asked about a set of physical activity guidelines, participants indicated that they needed to identify with the guidelines first before reading or applying them [23] and this often lead to comments that personal stories should be included in guidelines to help people relate to the information [22,23]. However, guidelines were also seen as an affirmation of patient experiences. In one study, women with menstrual disorders saw the guidelines as a way of reducing the need to 'prove' that they really had a menstrual problem because their individual needs were being identified in the guidelines [18].

\section{Theme 2: Purpose of guidelines for patient}

Nine studies described the potential purpose of guidelines for patients and the public and the role that guidelines have played to date $[6,15,16,19,21,22,27,31,38]$. Five studies reported that participants thought guidelines could be used as a simple tool to provide health information and recommendations which could lead to a better understanding of their health [15,16,21,22,38]. However, surveys conducted by SIGN and NICE found that only $8 \%$ of respondents thought guidelines were used to inform 
Table 3 Characteristics of studies and results for studies reporting awareness of clinical practice guidelines (17 included studies)

\begin{tabular}{|c|c|c|c|}
\hline Author year & Aim & Participants and study location & Awareness \\
\hline \multicolumn{4}{|l|}{ Study design } \\
\hline \multicolumn{4}{|l|}{ Quality } \\
\hline $\begin{array}{l}\text { Berry } 2010 \text { [23] } \\
\text { Qualitative study }\end{array}$ & $\begin{array}{l}\text { To gain an understanding of public } \\
\text { perceptions of Physical Activity } \\
\text { guidelines put forward by a public }\end{array}$ & $\begin{array}{l}22 \text { participants in five focus groups, } \\
18 \text { to } 70 \text { years; Type II diabetes or } \\
\text { cardiovascular disease; Canada }\end{array}$ & Lack of awareness \\
\hline
\end{tabular}

Good

Cameron 2007 [24]

Cross sectional study

Fair

Copeland 2005 [25]

Cross sectional study

Fair

Crocetti 2004 [26]

Cross sectional study

Good

Faruqi 2000 [16]

Qualitative study

Poor

Geiger 2001 [17]

Qualitative study

Fair

Hong 2007 [28]

Cross sectional study

Poor

Keenan 2002 [29]

Cross sectional study

Fair

Mitchell 2004 [19]

Qualitative study

Fair

Miroballi 2012 [31]

Cross sectional study

Fair

Nash 2003 [32]

Cross sectional study

Poor

McFarlane 2012 [30]

Cross sectional study

Fair

Owen-Smith 2010 [20]

Qualitative study

Fair health agency

To determine Awareness and Knowledge of Canadian Physical Activity Guide (CPAG) guidelines, prompted and unprompted

To determine awareness of written guidelines that define which conditions require exclusion from the Child Care Centre

To determine awareness and knowledge of infant feeding guidelines

To determine how to put into practice and disseminate clinical management of diabetes mellitus guidelines

To determine awareness of dietary guidelines and test presentation formats

To determine awareness and knowledge of dietary guidelines

To examine knowledge and understanding and factors that influence knowledge - media/ non-media/age and education

To examine knowledge of evidence based medicine and guidelines

To determine awareness of Infection Control guidelines

To determine cholesterol guideline awareness

To determine public awareness of National Institute for Health and Care Excellence (NICE) guidelines and their implementation

To investigate patients' and healthcare providers' experiences of, and preferences for, implicit and explicit healthcare rationing
8892 adults aged 18 or older from Physical Activity Monitor; 52\% female, $83 \%$ greater than high school education; Canada

128 parents picking up children at Day Care Centre, 91\% female, 69\% African American; Baltimore City, USA

102 Primary female caregivers mean age 27 years; 34\% African American; 64\% completed high school; Maryland, USA

5-20 participants recruited through Diabetes Australia in four focus groups; Sydney, Australia

40 men and women (25-45);

Missouri, USA

345 well people - 77\% female; $46 \%$ $<65$ years. Randomly selected in one district Seoul urban population.

400 adults over 18 years old, $51.8 \%$ college degree, $56 \%$ female;

Minnesota, USA

33 patients with colorectal cancer and 9 carers; 43 to 86 yrs old; $66 \%$ male; many had not completed high school; Austin, Victoria, Australia

1399 Cystic Fibrosis patients and their families; $38 \%$ patients, $62 \%$ family members in USA

1163 adults, 56\% female, $>40$ years; Canada

1675 respondents (70\% female, $61 \%$ (45-74 yrs old), 17\% health care professionals); mostly England and Wales, UK

56 participants (31 patients, clinicians, healthcare managers); morbid obesity and breast cancer; Bristol, UK
$4 \%$ aware of any guidelines for physical activity; 37\% prompted aware of CPAG

$61 \%$ aware of guideline

77\% aware of guideline

Lack of awareness

Lack of awareness

$32.2 \%$ aware of dietary guidelines

$45 \%$ aware of dietary guidelines

No awareness

$65 \%$ aware of guidelines

$32 \%(94 / 290)$ aware of guideline

79\% (824/1040) aware of guidelines

Only 6/31 patients knew about NICE and what they did and 3 of these patients worked for health service. 
Table 3 Characteristics of studies and results for studies reporting awareness of clinical practice guidelines (17 included studies) (Continued)

\begin{tabular}{|c|c|c|c|}
\hline $\begin{array}{l}\text { Roth } 2010 \text { [33] } \\
\text { Cross sectional study }\end{array}$ & $\begin{array}{l}\text { To investigate knowledge of } \\
\text { guidelines and if is this linked } \\
\text { to following guidelines }\end{array}$ & $\begin{array}{l}1940 \text { adolescents ( } 11-15 \text { yrs old); } \\
\text { 49\% female; England, UK }\end{array}$ & $\begin{array}{l}11 \% \text { of children knew about the } \\
\text { recommendations. }\end{array}$ \\
\hline Fair & & & \\
\hline $\begin{array}{l}\text { Royak-Schaler } 2008 \text { [22] } \\
\text { Qualitative study } \\
\text { Fair }\end{array}$ & $\begin{array}{l}\text { To investigate patient-physician } \\
\text { communication from the patient's } \\
\text { perspective about guidelines }\end{array}$ & $\begin{array}{l}39 \text { participants, } 30-75 \text { yrs old } \\
\text { (mean age 55), 72\% college } \\
\text { education, breast cancer survivors, } \\
\text { all African American; Baltimore, USA }\end{array}$ & Lack of awareness \\
\hline $\begin{array}{l}\text { SIGN } 2011 \text { [34] } \\
\text { Cross sectional study } \\
\text { Fair }\end{array}$ & $\begin{array}{l}\text { To investigate public awareness of } \\
\text { Scottish Intercollegiate Guidelines } \\
\text { Network (SIGN) guidelines and } \\
\text { their implementation }\end{array}$ & $\begin{array}{l}239 \text { respondents ( } 66 \% \text { female, } \\
74 \% 45-74 \text { yrs old, } 61 \% \text { had } \\
\text { specific condition or disability); } \\
\text { mostly Scotland, UK }\end{array}$ & $64 \%(151 / 236)$ aware of guidelines \\
\hline $\begin{array}{l}\text { Spence } 2002[36] \\
\text { Cross sectional study } \\
\text { Fair }\end{array}$ & $\begin{array}{l}\text { To investigate awareness of } \\
\text { Canada's Physical Guide to } \\
\text { Healthy Active Living }\end{array}$ & $\begin{array}{l}2719 \text { participants; } 18-76+\text { years; } \\
\text { Alberta, Canada }\end{array}$ & $20 \%(544 / 2719)$ aware of guideline \\
\hline
\end{tabular}

the public or dealt with advice for patients [30,34]. Patients also indicated that they could use guidelines to plan which questions they would ask their health care providers during the clinical encounter $[6,16,19,21,22,27,31,38]$. Guidelines, however, were not only useful for talking to doctors but they were also perceived as a tool that could be used independently, outside the consulting room. One study indicated that participants thought guidelines could help them make their own health care decisions [21] and in several studies, patients and the public identified guidelines as a source of information to manage their own care $[15,16,21,22,38]$. Breast cancer survivors felt guidelines could provide much needed recommendations regarding diet and physical activity [22]. Self- management was also important to diabetic patients who used guidelines to act as a good reminder for their own self-care [16]. Guidelines were not only considered useful for treatment but also for preventing disease [21]. Other studies reported that guidelines could also be used to ensure patients received the care to which they were entitled [20]; as a second opinion [21]; and as validation of their health problems [18].

There were however some concerns about the use of guidelines by patients. One study found that patients were worried that guidelines might impair the patientdoctor relationship by reducing confidence in the doctor and also through the potential to create conflict between patients and doctors [18]. Another study reported that patients felt that guidelines may take away decisionmaking from patients [6]. Finally there was concern about the trustworthiness of guidelines. In one study investigating the impact of recent modifications to an endocarditis guideline, if a patient's doctor did not approve of the guideline changes then patients would not follow it [27].

\section{Theme 3: Purpose of guidelines for health care system} and physician

Several studies indicated that patients thought guidelines had several purposes related to their care at a system level and the care provided by their health care providers $[6,16,18,20,30,34,35,38]$. Overall, participants' feelings were mixed about whether guidelines affected their care positively or negatively.

In several studies, guidelines were seen as a way to keep health care providers up to date with current treatments $[16,18]$ and also as a way to ensure consistent and high quality care [30,34]. The survey conducted by SIGN exploring the public's understanding of the purpose of guidelines indicated that $44 \%$ thought guidelines to be 'consistent best care/practice' [34]. In a similar survey conducted by NICE, $11 \%$ of participants thought that the main purposes of guidelines was 'Best care', and $8 \%$ thought NICE 'had something to do with fair access' [30]. In addition, 20/24 (84\%) of SIGN participants and 246/553 (45\%) NICE participants felt more confident in their or their relative's care and treatment as result of the relevant guideline being applied.

In contrast, many studies reported that participants thought guidelines may be rules that health professionals must follow rigidly $[6,18]$. Consequently, participants indicated that guidelines could lead to inflexibility in care provided to individual patients [18]; rationing or denial of care $[6,18,35]$; or limited access to innovative care that patients need [6]. Squiers found that participants felt that the breast screening guidelines may have been developed to restrict care or screening to particular groups, which can also lead to controversy if the guideline is misunderstood or controversial [35]. This viewpoint was also supported by the respondents to the NICE survey [30] with $11 \%$ believing cost effectiveness was one of the main purposes of guidelines. 


\section{Theme 4: Properties of guidelines}

A strong theme emerged in several studies: patients and the public emphasised the importance of formatting when trying to understand the guidelines and adapting the guidelines to themselves, and in how they perceived the guidelines. It was important to participants that the guidelines should be perceived as trustworthy. Berry et al. found that the simplistic format of the Canada Physical Activity Guideline, especially its use of cartoons, put people off [23] and that this undermined the guideline's trustworthiness:

When it came to participants' perceptions of [the guideline], they expressed a dislike for the cartoon-like format, which led some to actually question whether adults were the target audience and if the guide would be taken seriously.

Because of the use of cartoons participants felt they could not identify with the messages being put forward by the guideline.

Several studies found that a guideline's usefulness was also related to whether it was engaging to read and could hold a person's interest. Berry found that most participants thought the presentation of the guideline was dull and lacked the 'glitz' that would encourage people to pick up and read the guidelines [23]. Participants did not like to be presented with too much information [17] and liked information to be organised in layers (in particular on the internet), with quick access to layers of recommendations and the ability to drill down to get more detailed information [21].

Participants in many studies indicated that they wanted to know what to do and therefore the language needed to be clear and unambiguous [17,29,39]. People preferred simple phrases like 'low in fat' rather than more nuanced phrasing 'balance your fat' [17], and language that was specific and clear-cut [29]. Michie et al. [39] explored using 'behaviourally specific plain English' text, which had been amended using psychological theory to address potential barriers to implementing the guideline recommendations. This wording was perceived by patients and the public to lead "to stronger intentions to implement the guidelines, more positive attitudes towards them, and greater perceived behavioural control over using them" [39].

Two studies reported that variation in the quality of care, in research evidence and in treatment effectiveness, were genuinely new concepts for many people and it was unclear if guidelines were based on evidence [6]. Participants were unfamiliar with and sometimes confused by the terms 'medical evidence', 'quality guidelines' and 'quality standards' [6]. Despite this confusion, several studies reported that participants expressed a strong preference to be informed about the quality of evidence (or certainty or uncertainty) that supports a recommendation [37]. In particular, participants preferred to know about uncertainty relating to outcomes of a treatment or test but were slightly more interested in knowing about uncertainty relating to benefits than harms [37].

\section{Narrative synthesis of patient and public awareness of guidelines}

Seventeen studies focused on asking patients and the public about awareness of clinical guidelines, including those written for the public or professionals $[16,17,19,20,22-26,28-34,36]$.

Awareness that clinical guidelines exist ranged from $79 \%$ to $0 \%$. The largest numbers were found in the $(824 /$ 1040 ) of respondents to a NICE survey [30] (which respondents entered through the NICE website) and 64\% (151/236) (through the SIGN website) [34]. However, these results may represent awareness of an already 'aware' group of people. The smallest numbers were from few or no participants in focus groups when asked about their awareness of guidelines and/or guideline producers $[16,17,19,20,23]$.

Other studies asked patients and the public about awareness of a particular guideline after implementing strategies to improve awareness [19,23,32,33,36]. Berry et al. [23] and Spence et al. [36], focused on Canada's Physical Activity Guide to Healthy Living. Mitchell and White focused on the National Health and Medical Research Council colorectal cancer guidelines [19] and Nash et al. focused on national USA guidelines on managing cholesterol [32]. Whether or not participants were aware of a particular guideline, rather than guidelines in general, varied. Copeland et al. found in a survey that $61 \%(78 / 128)$ of parents were aware of illness exclusion guidelines from child care, though this was for any written guideline on illness exclusion rather than a named guideline [25]. Spence et al. found that 20\% (544/2719) of respondents to their survey were aware of Canada's Physical Activity Guide to Healthy Living [36] while Roth and Stamatakis found only around $11 \%$ of 1954 children aged 11-15 knew the key NICE recommendation for physical activity in children [33]. When asked about National Health and Medical Research Council colorectal cancer guidelines, none of 33 people with colorectal cancer taking part in interviews were aware of them, although all participants wanted a copy once they were made aware of them [19].

Keenan et al. examined consumers' knowledge of the 1995 Dietary Guidelines for Americans using a telephone survey of 400 adults in two cities and found that $55 \%$ of people had never heard of a document containing the government's dietary guidelines [29]. Of the 180 who knew it existed, 119 could not name it and only one of 
those who gave a name identified the Dietary Guidelines for Americans. Hong [28], found that 196/290 individuals interviewed about dietary guidance were not aware of the Dietary Guidelines for Korean, a sizeable minority $(64 / 290)$ felt that dietary guidelines were unnecessary. Crocetti et al. [26] surveyed 102 female caregivers at their child's 4 month well-child visit and found that 78\% were aware of the guideline and the specific recommendation of when to begin feeding solids [26].

Miroballi surveyed 1399 people who had, or who were caring for someone with, cystic fibrosis about infection control guidelines from the Cystic Fibrosis Foundation in the USA [31]. Overall, $65 \%$ of respondents were aware of the guidelines but of these only $66 \%$ had discussed them with their care team.

Royak-Schaler ran four focus groups with 39 African American breast cancer survivors and found that participants wanted guidelines that could help them develop plans for follow-up and survivorship self-care [22]. This guidance was available, however participants were neither provided with it, nor aware of it.

\section{Discussion}

The principal aim of the review was to identify and summarise patient and public attitudes to clinical practice guidelines. We found 26 studies of fair to good quality from which four main themes emerged: Applicability of guidelines, Purpose of guidelines for patient, Purpose of guidelines for health care system and physician, and Properties of guidelines. These themes represent patient and public attitudes to clinical practice guidelines which were written either specifically for health care providers or for patients and the public. We suggest that these themes may need to be incorporated into the design of patient versions of guidelines, to ensure their use.

For example, patients want to be seen as individuals with unique experiences and health care needs. The theme of Applicability to the individual, also known as 'Personalisation' or 'Affiliation', refers to the problems people have identifying with information and understanding the relevance to them, or what does it have to do with 'someone like me' [40]. Additional research is showing that conveying information is more than a question of whether patients understand the statistical risks (e.g. 3 out of 100 people were cured), but also how patients can use the information in their own situations [41]. Presenting personal stories of real people with the same health care needs may be one way to connect the reader to the information in guidelines, although there remains the question of how to select stories: should there be an attempt to provide balance, or should stories focus on the positive (or negative)? Perhaps guideline developers should pursue partnerships with patient organisations and popular 'patient story' websites such as healthtalkonline or PatientsLikeMe to provide direct access from patient stories to relevant guidelines-derived material. Alternatively, providing ways for readers to tailor the information to themselves by using their own health information may help individuals apply guidelines to their own particular situation. Decision aids, which guide people through a decision while clarifying personal values, can be provided as supplementary resources linked to guidelines and can be semi-automated as demonstrated in the MAGIC guideline project for antiantithrombotic therapy [42]. These guidelines, like others about Chronic Obstructive Pulmonary Disease, explicitly consider patient values and preferences when developing recommendations [43]; an approach the GRADE system has always considered when deciding the strength of a recommendation $[44,45]$. This is of particular importance in versions of guidelines intended to be used directly by the public.

Patients and the public also saw guidelines as potentially serving many purposes, such as being sources of health information, as tools for making decisions, or as a resource to manage their own care. Many guidelines, however, do not typically include background information about the conditions or the interventions covered in the guideline. This means it could be challenging for guideline producers to then develop patient versions as a source of general health information and it may require producers to dedicate additional resources to look outside the guideline for that information, even if only to signpost readers towards those other sources of information.

It is clear though that guidelines are different from other sources of health information: guidelines include evidence-informed recommendations about what should or should not be provided or done, something that other sources of information do not generally do. Thus the recommendations should not be lost when producing patient versions since these are what make guidelinederived material unique. But while some guidelines lend themselves to helping patients with recommendations about self-management (e.g. test your blood sugar daily), this may not be straightforward for other guidelines. Guideline producers committed to providing patient versions will need to consider each guideline individually to determine the intended purpose of the patient version.

Patients and the public did not always see guidelines in a positive light; we found that many consider guidelines as a way to ration and deny access to care. Guideline producers may need to overcome this barrier directly in the text of patient versions - perhaps by providing the evidence behind a recommendation to show where the recommendation came from, or to simply be explicit in saying that the aim of guidelines is not to ration care but to provide care based on the best evidence currently available. 
This review also found that public awareness of clinical guidelines is low, linked to the perception that clinical practice guidelines are only for health professionals and have little or no relevance for patients or the public. An increase in the number of guideline producers developing patient and public versions of all or some of their guidelines may help to address this awareness issue. Guideline producers cannot assume that patients and the public will naturally go to their websites looking for high-quality information, or that they will ask health professionals about guidelines. The material will need to be easily picked-up by search engines, as well as being promoted to health professionals to hand to patients, before significant numbers of the public will be able to use it in their decision-making.

\section{Methodological limitations}

The search was challenging as we could not filter our results by study design and our topic was broad (a problem also raised by others) [10]. However, we do not think we have missed any significant studies as we screened over 5000 citations and believe we have captured the most relevant studies for this review. We chose the widely used CASP tool to assess the quality of included studies, but we believe that it includes factors that may not be directly linked to the credibility of the results presented by the study (e.g. ethics approval). Therefore, studies scoring poorly on these factors may nevertheless have been higher quality which would further substantiate the results that we found. Regarding the degree of confidence we have in the synthesised results of this review, we have not provided an overall assessment. Although, there are methods to assess overall confidence in the quality of the evidence for reviews of interventions (e.g. GRADE), there is currently no agreed system to undertake this for syntheses of qualitative evidence. We have instead indicated that most results came from studies of good to fair quality and that the themes from this review of the literature may be important to consider when developing patient versions of clinical practice guidelines.

\section{Conclusions}

Many guideline producers are producing patient versions of clinical practice guidelines. This review has found important factors, in addition to formatting issues, which may affect the uptake and use of these versions of guidelines by public, patients and carers. Guideline producers need to make clear how the information is relevant to the reader and how it can be used to make healthcare improvements. In addition, awareness of guidelines is generally low and guideline producers cannot assume that the public has a more positive perception of their material than of alternative sources of health information.
Research to develop and test a variety of methods to incorporate this information into patient versions of guidelines is currently being conducted in the DECIDE project (Developing and Evaluating Communication Strategies to support Informed Decision and practice based on Evidence: http://www.decide-collaboration.eu). This project aims to improve the way guideline information is presented to a wide range of stakeholders, including the public, patients and their carers [7]. The intention is that by addressing the public's attitudes and awareness of clinical practice guidelines when producing versions of guidelines intended for the public, these will be more useful in supporting evidence-informed healthcare decision.

\section{Additional file}

Additional file 1: Search strategies for principal databases.

\section{Abbreviations}

CASP: Critical Appraisal Skills Programme; DECIDE: Developing and Evaluating Communication Strategies to support Informed Decision and practice based on Evidence; ENTEREQ: Enhancing transparency in reporting the synthesis of qualitative research; G-I-N: Guidelines International Network; GRADE: Grading of Recommendations Assessment, Development and Evaluation; NICE: National Institute for Health and Care Excellence; PRISMA: Preferred Reporting Items for Systematic Reviews and Meta-Analyses; SIGN: Scottish Intercollegiate Guidelines Network.

\section{Competing interests}

The authors declare that they have no competing interests.

\section{Authors' contributions}

All authors conceived of the review, screened studies, and read and approved the final manuscript. JH performed the searches. KL, MC and NS appraised the studies and abstracted data. $\mathrm{KL}$ and NS interpreted the data and wrote the review; ST also wrote the review.

\section{Acknowledgements}

The research leading to these results has received funding from the European Community's Seventh Framework Programme (FP7/2007-2013) under grant agreement $n^{\circ} 258583$ (DECIDE project). The Health Services Research Unit, Aberdeen University, is funded by the Chief Scientist Office of the Scottish Government Health Directorates. The authors accept full responsibility for this paper and the views expressed in it are those of the authors and do not necessarily reflect those of the Chief Scientist Office. NS receives funding through a Knowledge Translation Fellowship from the Canadian Institutes of Health Research. No funding bodies had a role in the manuscript. We would like to thank Healthcare Improvement Scotland and the University of Dundee for support, including access to literature. We would also like to thank Lorna Thompson (Healthcare Improvement Scotland), for her help with the protocol for this review.

\section{Author details}

${ }^{1}$ Division of Population Health Sciences, University of Dundee, Kirsty Semple Way, Dundee DD2 4BF, UK. ${ }^{2}$ McMaster University, Hamilton, Canada. ${ }^{3}$ Scottish Intercollegiate Guidelines Network, NHS Healthcare Improvement Scotland, Glasgow, Scotland. ${ }^{4}$ National Institute for Health and Care Excellence, Manchester, UK. ${ }^{5}$ Duodecim Medical Publications Ltd, Helsinki, Finland. ${ }^{6}$ Health Services Research Unit, University of Aberdeen, Aberdeen, UK.

Received: 19 December 2013 Accepted: 15 July 2014 Published: 27 July 2014 


\section{References}

1. Legare F, Boivin A, van der WT, Pakenham C, Burgers J, Legare J, St-Jacques S, Gagnon S: Patient and public involvement in clinical practice guidelines: a knowledge synthesis of existing programs. Med Decis Making 2011, 31(6):E45-E74.

2. How to develop patient versions of guidelines. [http://www.g-i-n.net/ document-store/working-groups-documents/g-i-n-public/toolkit/toolkitcombined.pdf]

3. van der Weijden $T$, Pieterse $A H$, Koelewijn-van Loon MS, Knaapen L, Legare F, Boivin A, Burgers JS, Stiggelbout AM, Faber M, Elwyn G: How can clinical practice guidelines be adapted to facilitate shared decision making? A qualitative key-informant study. BMJ Qual Saf 2013, 22(10):855-863.

4. van der Weijden T, Boivin A, Burgers J, Schunemann HJ, Elwyn G: Clinical practice guidelines and patient decision aids. An inevitable relationship. J Clin Epidemiol 2012, 65(6):584-589.

5. Graham ID, Logan J: Innovations in knowledge transfer and continuity of care. Can J Nurs Res 2004, 36(2):89-103.

6. Carman KL, Maurer M, Yegian JM, Dardess P, McGee J, Evers M, Marlo KO: Evidence that consumers are skeptical about evidence-based health care. Health Aff (Millwood) 2010, 29(7):1400-1406.

7. Treweek S, Oxman AD, Alderson P, Bossuyt PM, Brandt L, Brozek J, Davoli M, Flottorp S, Harbour R, Hill S, Liberati A, Liira H, Schünemann HJ, Rosenbaum S, Thornton J, Vandvik PO, Alonso-Coello P, DECIDE Consortium: Developing and Evaluating Communication Strategies to Support Informed Decisions and Practice Based on Evidence (DECIDE): protocol and preliminary results. Implement Sci 2013, 8:6.

8. Smith V, Begley CM, Clarke M, Devane D: Professionals' views of fetal monitoring during labour: a systematic review and thematic analysis. BMC Pregnancy Childbirth 2012, 12:166.

9. Dixon-Woods M, Agarwal S, Jones D, Young B, Sutton A: Synthesising qualitative and quantitative evidence: a review of possible methods. $J$ Health Serv Res Policy 2005, 10(1):45-53.

10. Munro SA, Lewin SA, Smith HJ, Engel ME, Fretheim A, Volmink J: Patient adherence to tuberculosis treatment: a systematic review of qualitative research. PLoS Med 2007, 4(7):e238.

11. Tong A, Flemming K, McInnes E, Oliver S, Craig J: Enhancing transparency in reporting the synthesis of qualitative research: ENTREQ. BMC Med Res Methodol 2012, 12:181.

12. Sanderson S, Tatt ID, Higgins JP: Tools for assessing quality and susceptibility to bias in observational studies in epidemiology: a systematic review and annotated bibliography. Int J Epidemiol 2007, 36(3):666-676.

13. Reeves BC, Deeks JJ, Higgins JP, Wells GA: Including non-randomized studies. In Cochrane Handbook for Systematic Reviews of Interventions. 510th edition. Edited by Higgins JP, Green S. Chichester: Wiley-Blackwell; 2011:391-429

14. Lucas PJ, Baird J, Arai L, Law C, Roberts HM: Worked examples of alternative methods for the synthesis of qualitative and quantitative research in systematic reviews. BMC Med Res Methodol 2007, 7:4.

15. Dykes PC, Currie L, Bakken S: Patient Education and Recovery Learning System (PEARLS) pathway: a tool to drive patient centered evidencebased practice. J Healthe Inf Manag 2004, 18(4):67-73.

16. Faruqi N, Frith J, Colagiuri S, Harris M: The use and perceived value of diabetes clinical management guidelines in general practice. Aust Fam Physician 2000, 29(2):173-176

17. Geiger CJ: Communicating dietary guidelines for Americans: room for improvement. J Am Diet Assoc 2001, 101(7):793-797.

18. Julian S, Rashid A, Baker R, Szczepura A, Habiba M: Attitudes of women with menstrual disorders to the use of clinical guidelines in their care. Fam Pract 2010, 27(2):205-211.

19. Mitchell PL, White CA, Austin Bowel Cancer C: Austin Bowel Cancer Consortium: changing culture in bowel cancer care. Med J Austr 2004, 180(10 Suppl):S79-S82

20. Owen-Smith A, Coast J, Donovan J: The usefulness of NICE guidance in practice: different perspectives of managers, clinicians, and patients. Int J Technol Assess Health Care 2010, 26(3):317-322.

21. Quintana Y, Feightner JW, Wathen CN, Sangster LM, Marshall JN: Preventive health information on the Internet. Qualitative study of consumers' perspectives. Can Fam Physician 2001, 47:1759-1765.

22. Royak-Schaler R, Passmore SR, Gadalla S, Hoy MK, Zhan M, Tkaczuk K, Harper LM, Nicholson PD, Hutchison AP: Exploring patient-physician communication in breast cancer care for African American women following primary treatment. Oncol Nurs Forum 2008, 35(5):836-843.

23. Berry TR, Witcher C, Holt NL, Plotnikoff RC: A qualitative examination of perceptions of physical activity guidelines and preferences for format. Health Promot Pract 2010, 11(6):908-916.

24. Cameron C, Craig CL, Bull FC, Bauman A: Canada's physical activity guides: has their release had an impact? Can J Public Health 2007, 98(Suppl 2):S161-S169.

25. Copeland KA, Duggan AK, Shope TR: Knowledge and beliefs about guidelines for exclusion of ill children from child care. Ambul Pediat 2005, 5(6):365-371.

26. Crocetti M, Dudas R, Krugman S: Parental beliefs and practices regarding early introduction of solid foods to their children. Clin Pediatr 2004, 43(6):541-547.

27. Elad S, Binenfeld-Alon E, Zadik Y, Aharoni M, Findler M: Survey of acceptance of the 2007 American Heart Association guidelines for the prevention of infective endocarditis: a pilot study. Quintessence Int 2011, 42(3):243-251.

28. Hong KE, Moon HK, Cho Sl, Ahn BC, Joung H: Awareness and perceived necessity of dietary guidelines among urban Koreans by gender. Nutr Res Pract 2007, 1(3):224-230.

29. Keenan DP, AbuSabha R, Robinson NG: Consumers' understanding of the Dietary Guidelines for Americans: insights into the future. Health Educ Behav 2002, 29(1):124-135.

30. McFarlane E, Thornton J, Chalmers S, Whittingham E, Sharma T, Alderson P: DECIDE: survey on awareness of NICE guidelines and their implementation. In G-IN Conference 2012, Berlin 2012. Dusseldorf: GMS Publishing House; 2012.

31. Miroballi $Y$, Garber E, Jia H, Zhou JJ, Alba L, Quittell LM, Angst D, Cabana M, Saiman L, CFICS Consortium: Infection control knowledge, attitudes and practices among cystic fibrosis patients and their families. Pediatr Pulmonol 2012, 47(2):144-152.

32. Nash IS, Mosca L, Blumenthal RS, Davidson MH, Smith SC Jr, Pasternak RC: Contemporary awareness and understanding of cholesterol as a risk factor: results of an American Heart Association national survey. Arch Int Med 2003, 163(13):1597-1600.

33. Roth M, Stamatakis E: Linking young people's knowledge of public health guidelines to physical activity levels in England. Pediatr Exer Sci 2010, 22(3):467-476

34. Voluntary Health Scotland: SIGN Guidelines: A Survey on Patient and Public Awareness. Edinburgh: Scottish Intercollegiate Guidelines Network; 2011. Available on request from sign@sign.ac.uk.

35. Squiers LB, Holden DJ, Dolina SE, Kim AE, Bann CM, Renaud JM: The public's response to the US Preventive Services Task Force's 2009 recommendations on mammography screening. Am J Prev Med 2011, 40(5):497-504.

36. Spence JC, Plotnikoff RC, Mummery WK: The awareness and use of Canada's physical activity guide to healthy active living. Can J Public Health 2002, 93(5):394-396.

37. Akl EA, Maroun N, Guyatt G, Oxman AD, Alonso-Coello P, Vist GE, Devereaux PJ, Montori VM, Schunemann HJ: Symbols were superior to numbers for presenting strength of recommendations to health care consumers: a randomized trial. J Clin Epidemiol 2007, 60(12):1298-1305.

38. Eaton CB, Parker DR, Borkan J, McMurray J, Roberts MB, Lu B, Goldman R, Ahern DK: Translating cholesterol guidelines into primary care practice: a multimodal cluster randomized trial. Ann Fam Med 2011, 9(6):528-537.

39. Michie S, Lester K: Words matter: increasing the implementation of clinical guidelines. Qual Saf Health Care 2005, 14(5):367-370.

40. Rosenbaum SE, Glenton C, Nylund HK, Oxman AD: User testing and stakeholder feedback contributed to the development of understandable and useful Summary of Findings tables for Cochrane reviews. J Clin Epidemiol 2010, 63(6):607-619.

41. Glenton C, Nilsen ES, Carlsen B: Lay perceptions of evidence-based information-a qualitative evaluation of a website for back pain sufferers. BMC Health Serv Res 2006, 6:34.

42. Vandvik PO, Brandt L, Alonso-Coello P, Treweek S, Akl EA, Kristiansen A, Fog-Heen A, Agoritsas T, Montori VM, Guyatt G: Creating clinical practice guidelines we can trust, use, and share: a new era is imminent. Chest 2013, 144(2):381-389

43. Kelson M, Akl EA, Bastian H, Cluzeau F, Curtis JR, Guyatt G, Montori VM, Oliver S, Schunemann HJ: Integrating values and consumer involvement 
in guidelines with the patient at the center: article 8 in Integrating and coordinating efforts in COPD guideline development. An official ATS/ERS workshop report. Proc Am Thorac Soc 2012, 9(5):262-268.

44. Andrews J, Guyatt G, Oxman AD, Alderson P, Dahm P, Falck-Ytter Y, Nasser M, Meerpohl J, Post PN, Kunz R, Brozek J, Vist G, Rind D, Akl EA, Schünemann HJ: GRADE guidelines: 14. Going from evidence to recommendations: the significance and presentation of recommendations. J Clin Epidemiol 2013, 66(7):719-725.

45. Atkins D, Best D, Briss PA, Eccles M, Falck-Ytter Y, Flottorp S, Guyatt GH, Harbour RT, Haugh MC, Henry D, Hill S, Jaeschke R, Leng G, Liberati A, Magrini N, Mason J, Middleton P, Mrukowicz J, O'Connell D, Oxman AD, Phillips B, Schünemann HJ, Edejer T, Varonen H, Vist GE, Williams JW Jr, Zaza S, GRADE Working Group: Grading quality of evidence and strength of recommendations. BMJ 2004, 328(7454):1490.

doi:10.1186/1472-6963-14-321

Cite this article as: Loudon et al.: Patient and public attitudes to and awareness of clinical practice guidelines: a systematic review with thematic and narrative syntheses. BMC Health Services Research 2014 14:321.

\section{Submit your next manuscript to BioMed Central and take full advantage of:}

- Convenient online submission

- Thorough peer review

- No space constraints or color figure charges

- Immediate publication on acceptance

- Inclusion in PubMed, CAS, Scopus and Google Scholar

- Research which is freely available for redistribution 